\title{
Study of Sulfur Oxide Reduction During Combustion of Coal-Water Slurry
}

\author{
Murko Vasiliy I. a, Karpenok Viktor I. a , Senchurova \\ Yuliy A. ${ }^{a}$, Khyamyalyainen Veniamin A. ${ }^{\text {b }}$ \\ T.F. Gorbachev Kuzbass State Technical University \\ Kemerovo, Russian Federation \\ a sib_eco@kuz.rubvah@kuzstu.ru
}

\begin{abstract}
It is shown that use of coal-water slurry fuel (CWF) is most preferable for reduction of sulfur oxide content during combustion of coal fuel by feeding of sulfur capture agents (SCA) in the burning area. The technique of thermodynamic analysis of chemical reactions in the process of CWF burning was developed. In this case, the optimal temperature conditions have been determined as required for the effective reduction of sulfur oxides in flue gases when using different types of SCA. According to the results of calculating the composition of CWF combustion products when entering various substances in the burner space as SCA it has been determined that magnesite, calcite, and dolomite are the most effective natural minerals. The reliability of the results obtained is confirmed by experimental studies of burning CWFs prepared from Bulgarian high-sulfur coal
\end{abstract}

Keywords- sulfur capture agent; water-coal slurry fuel; thermodynamic analysis; vortex combustion of coal fuel

\section{INTRODUCTION}

It is known [1] that addition of SCA in the combustion area is one of the effective methods of reducing the content of sulfur oxides in flue gases produced by combustion of various fuels including coal fuels. When using this option of sulfur capture it is preferable to use ecologically clean water-coal slurry fuel as coal fuel which already contains sulfur capture agent added at the stage of fuel preparation. The main point of this option of sulfur capture is that certain chemical elements present in the SCA interacting with sulfur or sulfur-containing substances formed in the combustion process chemically interact to form new solid phase sulfur compounds. In this process, a part of the resulting substances falls in the slag funnel of the boiler and is removed from the boiler with the boiler ash and slag, while the remaining part is carried out of the boiler with the flue gases in the form of fines and is captured by the gas treatment system. It is possible to make a preliminary evaluation of the effectiveness of SCA elements impact on the sulfur binding process during combustion using chemical thermodynamics methods and in particular the thermodynamic analysis. With regard to the chemical reactions occurring in the area of coal fuel combustion, it can be argued that subject to environmental conditions (pressure, temperature, composition of substance in the system) corresponding to the equilibrium state and sufficient time for such an interaction, the chemical response of substances

\author{
Tailakov Oleg V. ${ }^{c}$ \\ T.F. Gorbachev Kuzbass State Technical University, \\ Institute of Coal, SB RAS Federal Research Centre of Coal \\ and Coal Chemistry \\ Kemerovo, Russian Federation \\ ctailakov@uglemetan.ru
}

located in the furnace space will provide the required (estimated) composition of combustion products. The required time of the reactive agents staying in the reaction area during combustion of various types of coal fuel is ensured by a rational choice of combustion technology and management of the combustion process.

Recently, swirl method of coal fuels combustion has become widely spread, including fuels significantly filled with water or mineral components [2]. This method of combustion provides good mixing of fuel and air, their rapid heating and thereby substantially uniform reactants distribution over the combustion chamber.

\section{MATERIALS AND Methods}

It is known [3] that in the chemical thermodynamics finding of conditions ensuring the reduction of the system to an equilibrium state is equivalent to the definition of the system parameters characterizing it when it reaches the state of equilibrium. It is necessary for the use of thermodynamic analysis to determine the chemical composition of this mixture and process conditions in the presence of SCA in which the equilibrium state of the system is achieved. Thus in the composition of substances of the system in addition to conventional gaseous substances formed during combustion of wet coal fuel (carbon dioxide, water vapor) and solid ash and slag forming substances, there must be solids containing sulfur present and there should be no gaseous sulfur oxides. As a consequence, it is possible to obtain a complete binding of sulfur in the composition of solids, capture and removal of the latter from the process presents no particular technical difficulties. The results of the thermodynamic analysis need to be confirmed by the results of field experiments.

In this connection, the technique of thermodynamic analysis of coal fuels burning was developed including burning in the presence of SCA. In accordance with the developed technique, the program was developed for calculation of coal fuels burning products composition, in particular for coal-water slurry fuel, provided that various substances were entered in the burner space as SCA. The block diagram of the program is shown in Fig. 1.

The calculation made using the developed programme showed that such natural minerals as magnesite, calcite, and 
dolomite were the most efficient SCAs. The developed technique provided good correlation of the results of calculations and field experiments performed on the demonstration stand during combustion of high-sulfur Bulgarian coals.

Initial data input. Set up the chemical composition of the mass to be fed to combustion chamber

$$
\downarrow
$$

Calculate mole composition of substances entering the combustion chamber including elementary fuel composition, mineral composition of its ash part as well as SCA composition
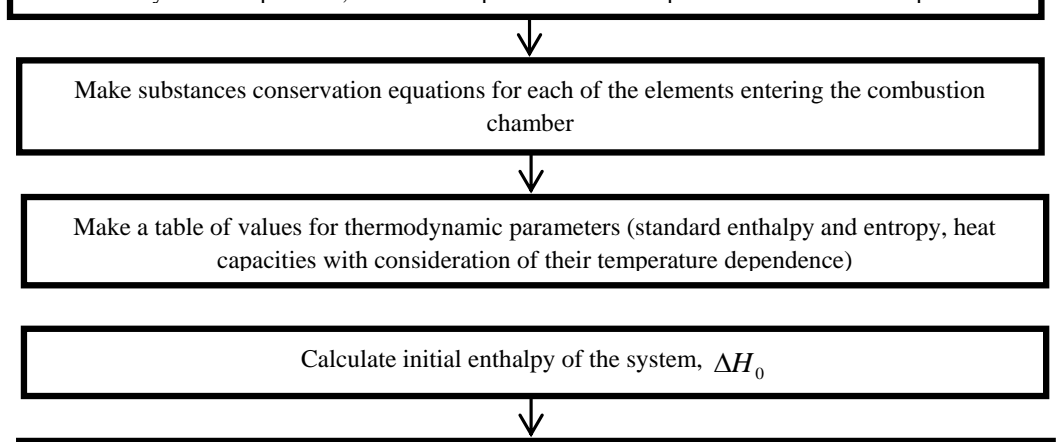

Set up temperature interval within which the thermodynamic study is being made, $T_{\min }, T_{\max }$

\section{$\downarrow$}

Set up initial temperature which the thermodynamic study is being made, $T_{0}$

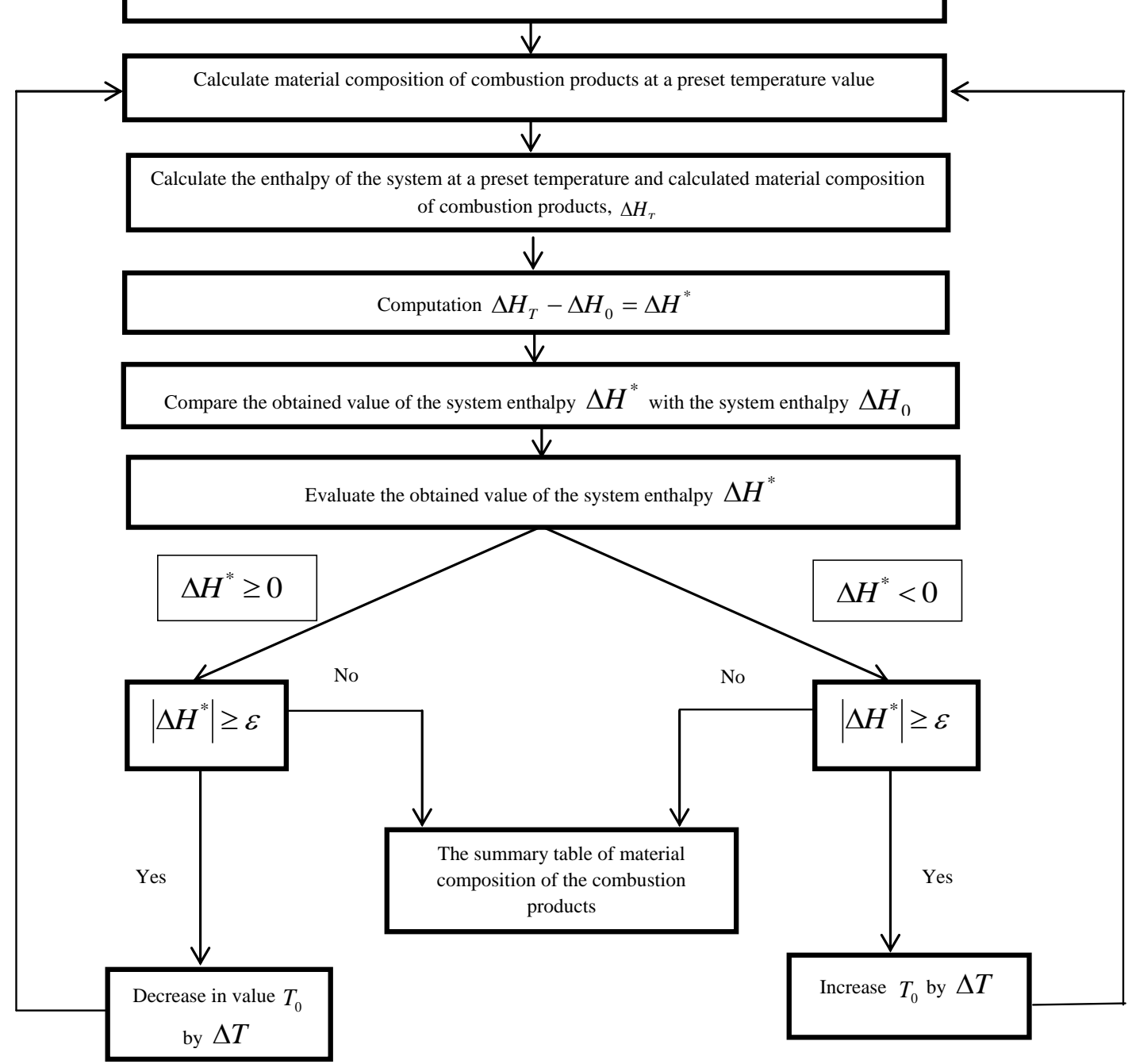

Fig. 1. Block diagram for execution of the program of thermodynamic analysis 
TABLE I. QUALITY SPECIFICATIONS OF THE INPUT COAL AND CWF PREPARED THEREFROM

\begin{tabular}{|c|c|c|c|c|}
\hline Property description & Symbol & $\begin{array}{c}\text { Unit of } \\
\text { measure }\end{array}$ & Coal from the Black Sea Mine & CWF \\
\hline Moisture, total & $W_{*}^{E}$ & $\%$ & 20 & 55 \\
\hline Ash (dry basis) & $\mathrm{A}^{\mathrm{d}}$ & $\%$ & 31 & \\
\hline $\begin{array}{l}\text { Volatile matters (dry ash-free } \\
\text { basis) }\end{array}$ & $\mathrm{V}^{\mathrm{daf}}$ & $\%$ & $50-60$ & \\
\hline $\begin{array}{l}\text { Sulfur, total } \\
\text { (dry basis) }\end{array}$ & $S_{E}^{\frac{d}{2}}$ & $\%$ & $\begin{array}{c}3.8 \\
\text { including combustible sulfur (organic and } \\
\text { pyritic) }-2.4 ; \\
\text { incombustible (sulphate) - } 1.4 \\
\end{array}$ & \\
\hline Net calorific value, as received & $\overline{Q F}$ & $\mathrm{kcal} / \mathrm{kg}$ & 3,600 & 1,750 \\
\hline
\end{tabular}

\section{RESULTS AND DISCUSSIONS}

The coal from The Black Sea Mine of the Republic of Bulgaria was used to prepare CWF. The properties of the coal and CWF prepared therefrom are shown in Table 1.

The experimental batches of CWF were prepared at a demonstration pilot stand unit (Fig. 2).

The CWF preparation unit is comprised of a storage bunker, an auger proportioning feeder, a vibration mill, a holding tank for water solution of a plasticizer, pipeline for proportioned feeding of the plasticizer solution with a flowmeter, control and stop valves, a sieve to catch coal particles $>3 \mathrm{~mm}$ in the finished product, a sump for receiving finished CWF from the mill, an agitator pump, a pump unit to feed the finished CWF in the storage container.

The pilot batches of CWF were burned at the experimental stand unit (Fig. 3).

Combustion of CWF was carried out in a special vortex combustion chamber equipped with a burner and a gas evacuation system. CWF was fed in a metered flow from the supply tank by a peristaltic pump with a capacity of up to 0.3 $\mathrm{m} 3 / \mathrm{h}$ along the pipeline system to the nozzle of the burner. The feed was regulated by the inverter by changing the pump motor RPM. To eliminate clogging of nozzles by large particles and foreign objects, the self-cleaning filter was used.

Spraying of CWF was carried out by compressed air from the compressor. The diesel fuel torch was used for the initial warm-up of the furnace and the ignition. The temperature in the combustion chamber and flue gas ducts was controlled by thermocouples. CWF pressure and compressed air pressure was measured by pressure sensors. Consumption of CWF and compressed air was controlled by flow meters. All pressure and temperature readings were recorded on process meters. During CWF combustion test the composition and temperature of the flue gases was controlled on a constant basis using a gas analyzer. Consumption of $\mathrm{CWF}$ at the temperature in the furnace within $1000-1050{ }^{\circ} \mathrm{C}$ was $70-100 \mathrm{l} / \mathrm{h}$. When CWF produced of The Black Sea Mine coal was burned without SCA, the characteristic odor of sulfur compounds was felt in the room.

The SCA was prepared as a suspension based on limestone $\left(\mathrm{CaO}-46.3 \% ; \mathrm{MgO}-6.1 \% ; \mathrm{CaCO} 3+\mathrm{MgCO}_{3}-98.1 \%\right)$. SPA consumption for each combustion was calculated based on the stoichiometric ratio required for binding of total sulfur in each coal sample (including sulfate). Feeding of SCA solution in WCF samples was carried out by its dosing and mixing in a mortar mixer. The prepared WCF and SCA mixture was fed in

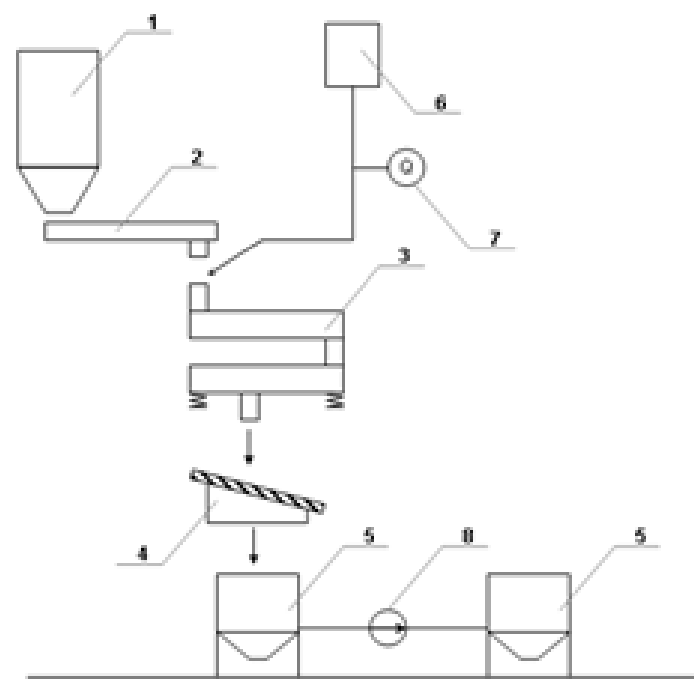

\author{
1 - Storage bunker \\ 2-Augerproportioning feeder \\ 3 - Vibration mill VM- 60 \\ 4 - Sieve $(3 \mathrm{~mm})$ \\ 5 - Fininshed product sump \\ 6 - Holding tank for the water solution of a \\ plasticizer \\ 7 - Plasticizer flowmeter \\ 8 - Agitator pump
}

Fig. 2. Process diagram of CWF preparation 


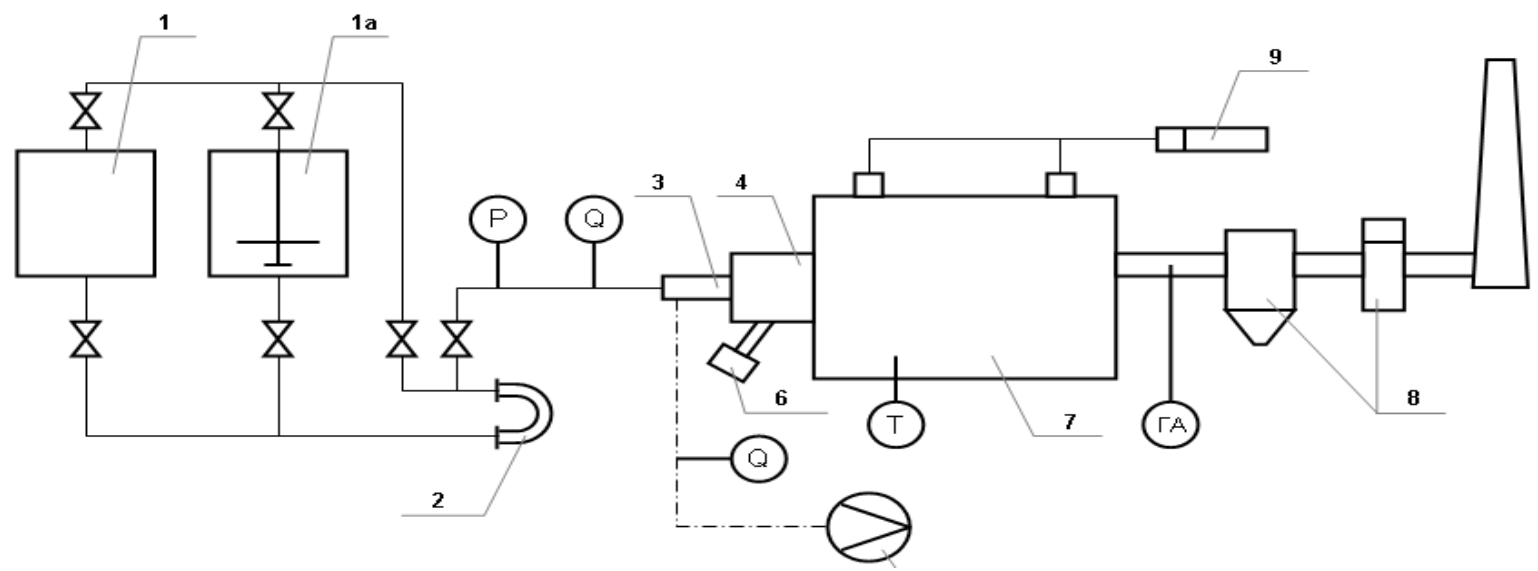

1 - CWF storage tank; 1a - Agitation tank with a mixer for storage of CWF with sulfur capture agent; 2 - Hose pump NP-16; 3 - CWF nozzle; 4 - Burner arrangement; 5 - Compressor; 6 - Start-up burner; 7 - Combustion chamber; 8 - Flue gas evacuation system.; 9 - Blowing fan.

Fig. 3. Scheme of CWF burning unit

portions to the furnace for combustion. Technologically the tests were conducted in two series.

In the first series, the best modes of burning WCF were determined without SCA, in the second - with SCA.

To ensure the highest efficiency of the furnace and maximum efficiency of fuel combustion, blast air supply was varied with a change in the excess air ratio within a range of $1.1 \div 1.2$ to $1.4 \div 1.5$. As a result, an almost total combustion of coal carbon $(98 \div 100 \%)$ and a complete combustion of the volatile components of coal was ensured.

The results of burning CWF with SCA demonstrated the ability to bind $\mathrm{SO}_{2}$ in solid sulfate compounds. At the same time, a reduction in the concentration of $\mathrm{SO}_{2}$ in flue gases by $1,5 \div 2,0$ times was achieved (Fig. 4).

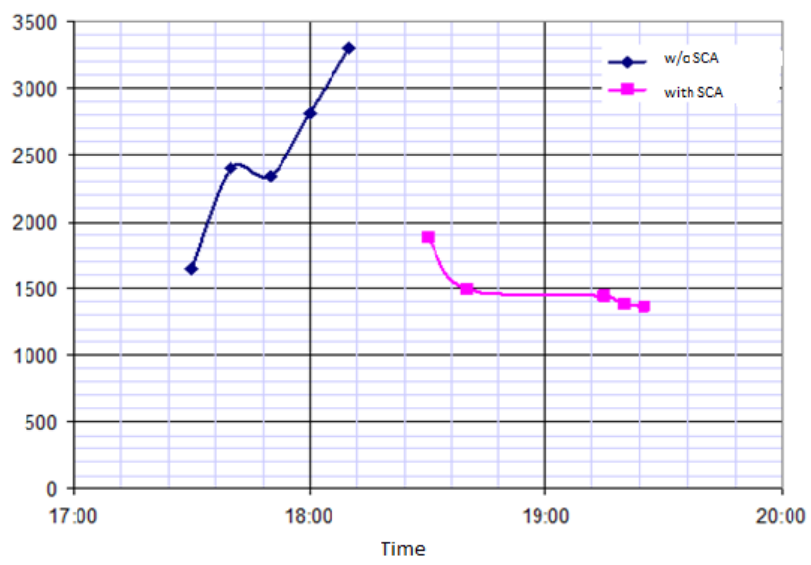

Fig. 4. The impact of SCA on the reduction of SO2 content in flue gases during CWF combustion

\section{CONCLUSION}

The thermodynamic analysis and the results of experiments have shown that the use of SCA for burning CWF in the vortex furnace ensure significant reduction of $\mathrm{SO}_{2}$ content in flue gases (by $1.4 \div 2.0$ times).

\section{ACKNOWLEDGMENT}

The work was performed with the financial support of the state in the name of the Ministry of Education and Science of the Russian Federation within implementation of the Federal target program 'Research and Development in the Priority Directions of Development of the Scientific and Technological Complex of Russia for 2014-2020', as per Agreement №14.583.21.0004 on the subsidy granting of July 16, 2014. The unique identifier of scientific research (project) is RFMEFI58314X0004.

\section{REFERENCES}

[1] Ismaguilov Z.R., Tailakov O.V., Teryaeva T.N. et al. Development of Effective Technology for Reduction of Flue Gases Pollution at Thermal Power Stations of Coal Generation. Coal. 2015. \#.9. pp.57-60.

[2] Murko V.I., Dzhundubaev A.K., Baranova M.P., Biybosunov A.I., Kulagin V.A. Slurry Fuel Transporting and Energy Complexes/RussianKyrgyz Scientific and Technical Cooperation in the Field of Power Engineering. Krasnoyarsk: Siberian Federal University. 2015. p. 250.

[3] Krestovnikov A.N., Vigdorovitch V.N. Chemical thermodynamics.1973. p. 256

[4] K. Elissa, "Title of paper if known," unpublished. 